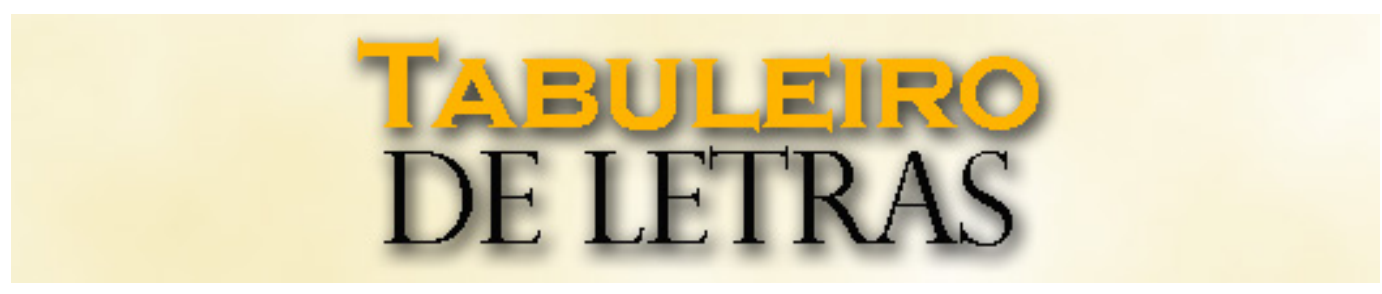

\title{
O Falar Baiano e o Falar Fluminense a partir dos dados do Projeto ALiB
}

\author{
The Baiano speech and the Fluminense speech from the ALiB Project data
}

\begin{abstract}
Leandro Almeida dos Santos ${ }^{1}$
RESUMO: Neste artigo são apresentados alguns aspectos sobre delimitação de áreas dialetais. Desse modo, este trabalho investiga as respostas dos informantes do Atlas Linguístico do Brasil (ALiB) para a questão 166 do Questionário Semântico-Lexical do ALiB, "Como se chama uma tábua, pendurada por meio de cordas, onde uma criança se senta e se move para frente e para trás?” (COMITÊ NACIONAL DO PROJETO ALiB, 2001, p. 34). A metodologia utilizada pautou-se em: a) leitura de textos teóricos acerca do tema em questão; b) formação do corpus; e c) análise do corpus, objetivando identificar as variações diatópicas, a partir do cotejo com estudos semelhantes, a saber: Ribeiro (2012) e Santos (2016), os quais se utilizaram dos dados do ALiB, em especial, o campo semântico dos jogos e diversões infantis, no intuito de testar, hoje, com base em dados empíricos, a divisão dialetal brasileira, datada de 1953. As análises buscam identificar os itens encontrados nas elocuções dos informantes e verificar o que essas escolhas revelam, com vistas a apurar a vitalidade da divisão dialetal de Nascentes (1953). Vale ressaltar a contribuição do trabalho, catalogar a diversidade lexical da língua falada no país, em busca de oferecer, se possível, um traçado atual dos limites dos falares brasileiros, embora seja uma tarefa árdua, mas que vem sendo perseguida pelos dialetólogos brasileiros.
\end{abstract}

Palavras-chave: Áreas dialetais; Jogos e brincadeiras; Léxico.

\begin{abstract}
In this article we present some aspects about the delimitation of dialectal areas. Thus, this work investigates the responses of the informants of the Brazilian Linguistic Atlas (AliB) to question 166 of ALiB's Semantic-Lexical Questionnaire, "As it is called a board, hung by ropes, where a child sits and Move back and forth? "(NATIONAL PROJECT COMMITTEE ALiB, 2001, p.34). The methodology used was based on: a) reading theoretical texts about the subject in question; B) formation of the corpus; And c) analysis of the corpus, aiming to identify the diatopic variations, from the comparison with similar studies, namely: Ribeiro (2012) and Santos (2016), which were used from the ALiB data, especially the semantic field of games and children's amusements, in order to test, today, based on empirical data, the Brazilian dialectal division, dated 1953. The analyzes seek to identify the items found in the statements of the informants and verify what these choices reveal, in order to Vitality of the nascent dialectal division (1953). It is worth emphasizing the contribution of the work, to catalog the lexical diversity of the language spoken in the country, in order to offer, if possible, a current outline of the limits of Brazilian speeches, although it is an arduous task, but has been pursued by Brazilian dialecologists.
\end{abstract}

Keywords: Dialectal areas; Games and activities; Lexicon.

\footnotetext{
${ }^{1}$ Professor da Faculdade Montessoriano (FAMA) e da Faculdade Regional da Bahia (UNIRB). Mestre e Doutorando pelo Programa de Pós-Graduação em Língua e Cultura - UFBA. E-mail: santosleo1811@gmail.com
} 


\section{Introdução}

O artigo apresenta uma análise sobre a proposta de divisão dialetal do Brasil de Nascentes (1953), a partir dos resultados obtidos para a pergunta 166 - "Como se chama uma tábua, pendurada por meio de cordas, onde uma criança se senta e se move para frente e para trás?" (COMITE NACIONAL DO PROJETO ALiB, 2001, p. 34) - pertencente ao Questionário Semântico-Lexical do Projeto Atlas Linguístico do Brasil (ALiB). Para o intento, optou-se por fazer um cotejo com estudos que utilizaram a mesma pergunta, a fim de verificar a vitalidade da referida proposta, embora em áreas diferentes, a saber: Ribeiro (2012) - Falar Baiano - e Santos (2016) - Falar Fluminense.

O objetivo principal do artigo é oferecer aos interessados na temática, sobretudo aos dialetólogos, informações sobre a atualidade da proposta de divisão dos falares do Brasil, estabelecida por Nascentes (1953), no que tange à delimitação dos falares. Nessa perspectiva, utilizaram-se os pressupostos da Dialetologia Pluridimensional e da Sociolinguística Laboviana, tendo em vista que a língua, certamente, é mutável, e por isso mesmo a variação e a mudança são inerentes a ela. Logo, tanto a primeira quanto a segunda não acontecem de forma aleatória, porém são condicionadas a fatores passíveis de observação e sistematização.

Vale destacar que o artigo se justifica pela necessidade de aprofundamento nas pesquisas sobre áreas dialetais brasileiras, principalmente no tocante às áreas investigadas Falar Baiano e Falar Fluminense -, haja vista que as descobertas podem fornecer caminhos para o reconhecimento, sistematização e caracterização das áreas e possíveis subáreas linguísticas. Ademais, ao estudar a língua e os aspectos lexicais, podem ser descobertas muitas informações linguísticas e sociais que servirão para um melhor tratamento da variação e mudança linguísticas, no espaço escolar e nos mais variados espaços sociais.

Portanto, é elementar frisar que são necessários outros estudos, por sua vez, mais aprofundados, para um reconhecimento das várias características dialetais brasileiras. Com isso, a diversidade do Português Brasileiro (doravante PB) é reconhecida e assumida como condição fulcral para o estudo, uma vez que, ao observar o contexto em que foi disseminada e implantada a língua portuguesa, encontram-se motivos reais para tal crença.

2 Panorama sobre áreas dialetais do Brasil 
Na Geolinguística do Brasil podem ser encontradas propostas de divisão dialetal. Dentre elas, em 1953, destaca-se uma proposta, a de Antenor Nascentes, que surgiu após o estudo, crítica e reformulação das proposições feitas por outros autores e por Nascentes, como pode ser visto a seguir:

a) Divisão dialetal proposta por Júlio Ribeiro, em 1881.

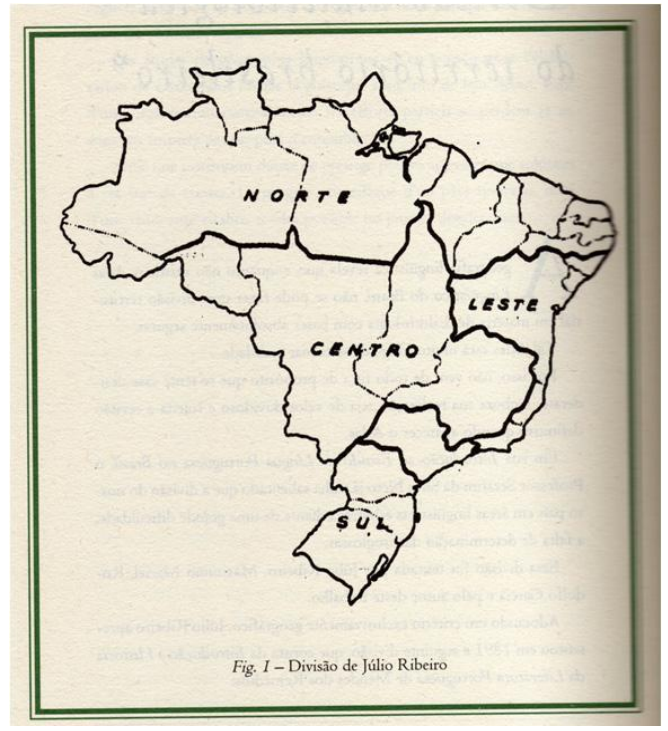

Figura 1: Divisão dialetal de Júlio Ribeiro (1891) Fonte: BARBADINHO NETO (2003, p. 692)

Ao estabelecer um único critério, o geográfico, Ribeiro (1881) separou o território brasileiro em quatro grandes áreas: Norte; Leste; Centro e Sul. Nascentes considerou a proposta defeituosa, pois, segundo ele, existem alguns equívocos como, por exemplo, “[...] junta o Norte com o Nordeste... separa Alagoas dos demais estados do Nordeste; coloca o Espírito Santo e o Rio de Janeiro junto da Bahia...” (NASCENTES, 1953, p. 21), entre outros.

b) Divisão dialetal proposta por Maximino Maciel, em 1950. 


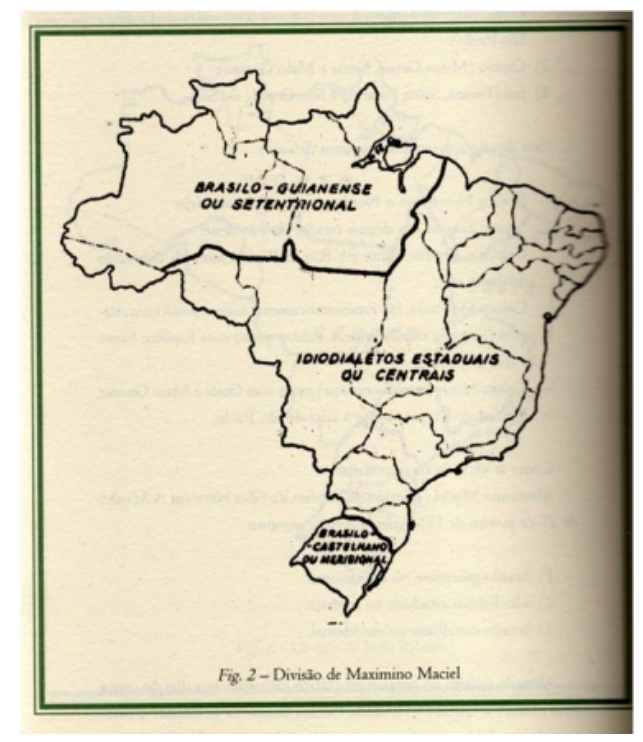

Figura 2: Divisão dialetal de Maximino Maciel (1950) Fonte: BARBADINHO NETO (2003, p. 694).

Baseado no aspecto geográfico, Maciel (1950) apresenta uma divisão tripartida: basiloguianense ou setentrional; idiodialetos estaduais ou centrais e basilo-castelhano ou meridional. Nascentes avaliou a proposta e identificou problemas, pois, além do exclusivo fundamento geográfico, o autor aponta que:

[...] A língua chamada Guiana Brasileira se estende à região da margem direita do Amazonas; que serão idiodialetos? A influência do castelhano platino na língua da fronteira com o Uruguai e com a Argentina não vai ao ponto de dominar um subfalar. (NASCENTES, 1953, p. 21).

\section{c) Divisão dialetal proposta por João Ribeiro, o historiador.}

Na obra História do Brasil, sem data, João Ribeiro propõe a seguinte divisão: o extremo norte - Amazônia; Maranhão, Piauí e Ceará; o norte - Alagoas, Pernambuco, Paraíba e Rio Grande do Norte; o centro - Sergipe, Baía, Ilhéus, e Porto Seguro; o interior - São Paulo, Minas Gerais, Goiás e Mato Grosso; o sul - Espírito Santo, Rio de Janeiro, Santa Catarina e Rio Grande do Sul. Portanto, possui 5 grupos. (NASCENTES, 1953, p. 23). Este autor considera válida a proposta, pois foi pautada em critérios históricos, contudo ele apresenta e discute outra proposta de divisão dialetal.

\section{d) Divisão dialetal proposta por Rodolfo Garcia, em 1915.}


A proposta de Rodolfo Garcia (1915) leva em consideração os aspectos geográficos e históricos, além da continuidade territorial, os aspectos culturais semelhantes e diferentes, a facilidade de comunicações terrestres, marítimas e fluviais e, por fim, os glossários com expressões locais. O referido autor organiza o País em cinco zonas: norte; norte-oriental; central-marítima; meridional e altiplana-central. Conforme Nascentes (1953), é "uma divisão mais aceitável”, mas mesmo assim o autor aponta vários defeitos como, por exemplo:

[...] Coloca o Maranhão na zona Norte, quando ele é uma espécie de intermediário entre ela e o Nordeste; Coloca o Rio de Janeiro e o sul do Espírito Santo na zona central-marítima; Coloca Minas Gerais (sem discriminar) e Goiás junto com Mato Grosso. (NASCENTES, 1953, p. 21).

\section{e) Divisão dialetal proposta por Antenor Nascentes, em 1922.}

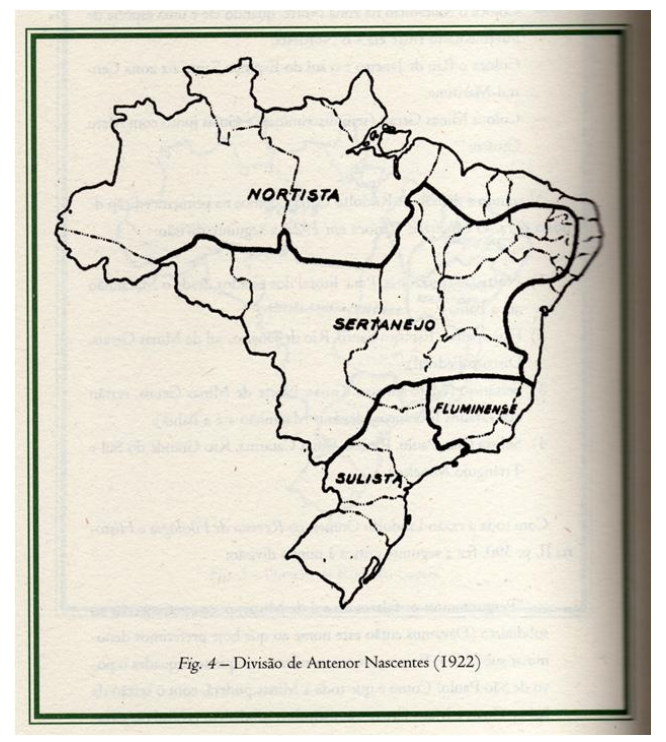

Figura 4: Divisão dialetal de Antenor Nascentes (1922) Fonte: BARBADINHO NETO (2003, p. 698).

Na obra O Linguajar Carioca em 1922, ao analisar a proposição de Rodolfo Garcia, Antenor Nascentes apresenta uma divisão, e nela o país encontra-se subdividido nos seguintes falares: Nortista; Fluminense; Sertaneja e Sulista. Tal proposição, também, foi alvo de comentários críticos por parte de geógrafos e historiadores. Mas, em 1933, a partir das considerações feitas por Lindolfo Gomes, Nascentes reformula a divisão anteriormente feita. Logo, a proposta de 1922 foi reelaborada em 1953, publicada na obra O linguajar carioca, a saber: 
Hoje que já realizei o meu ardente desejo de percorrer todo o Brasil, do Oiapoc ao Xuí, de Recife a Cuiabá, fiz nova divisão que não considero nem posso considerar definitiva, mas sim um tanto próxima da verdade. [...] Dividi o falar brasileiro em seis subfalares que reuni em dois grupos a que chamei do norte e do sul. (NASCENTES, 1953, p. 24-25).

Com base em dois fatos linguísticos, embora a pesquisa tenha sido feita pelas impressões do referido autor, é a proposta na qual vários estudos de estudos críticos têm se debruçado, a fim de verificar a vitalidade das proposições de Nascentes (1953), conforme Figura 5:

f) Divisão dialetal proposta por Antenor Nascentes, em 1953.

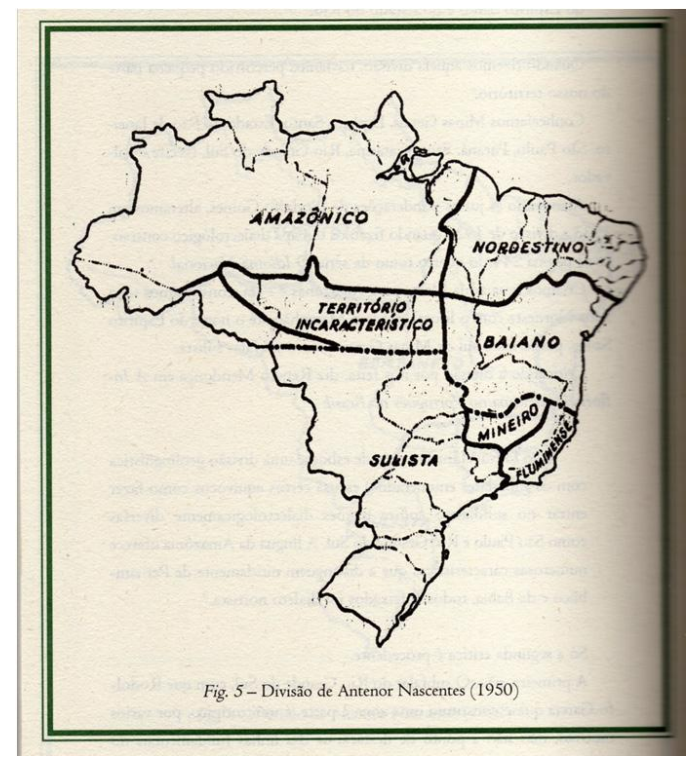

Figura 5: Divisão dialetal de Antenor Nascentes (1933/1953) Fonte: BARBADINHO NETO (2003, p. 700)

Ao observar a cadência e abertura das vogais médias em posição pretônica, Nascentes (1953) reparte o Brasil em duas grandes áreas dialetais - os falares do Norte (que contêm dois subfalares: o Amazônico e o Nordestino) e os falares do Sul (que contêm quatro subfalares Baiano, Fluminense, Mineiro e Sulista). Ademais, o referido autor afirma a existência de um território incaracterístico. Sabe-se, com isso, que a delimitação estabelecida por Nascentes (1953) é, indiscutivelmente, uma referência bastante importante e bem utilizada para os estudos fonéticos, lexicais e morfossintáticos, que tem como centro de interesse a "delimitação de áreas dialetais". (MOTA, 2006, p. 321).

É pertinente mencionar alguns trabalhos que fazem alusão a áreas dialetais. Nesse sentido, as considerações feitas por Zágari (2005) ganharam grande vulto, uma vez que, 
contrariando as ideias de Nascentes (1953), com base na pesquisa empreendida para elaboração do Esboço de um Atlas Linguístico de Minas Gerais (EALMG), o autor estabelece três falares em Minas Gerais: baiano; paulista e mineiro, conforme Figura 6.

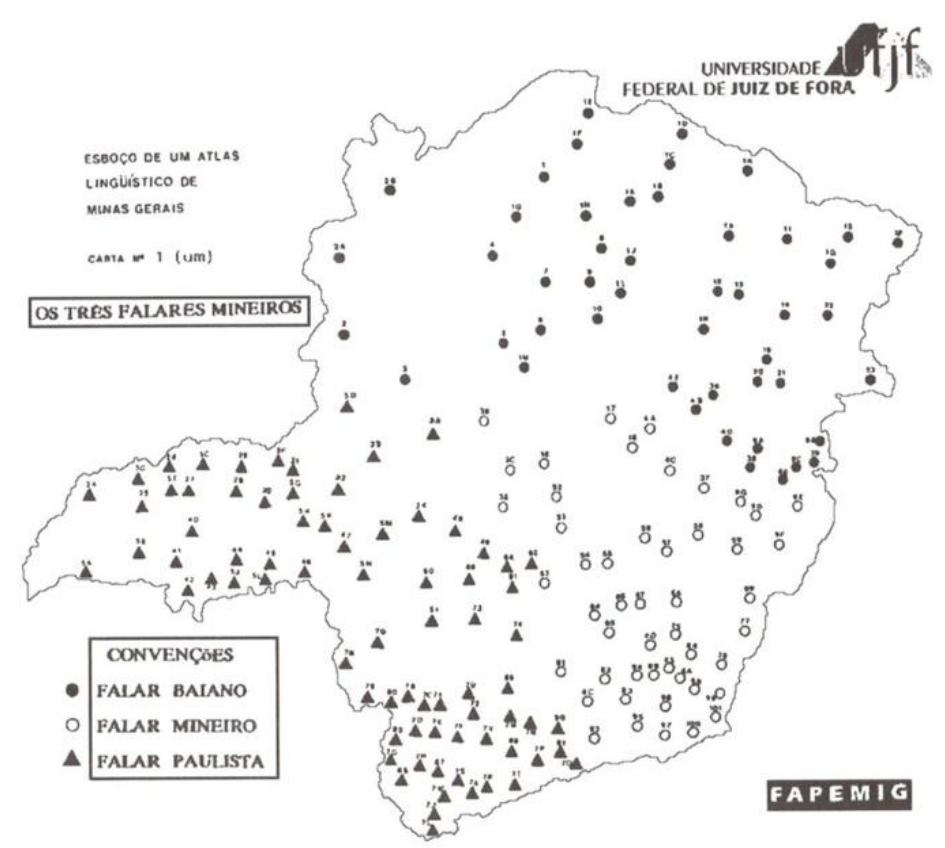

Figura 6: Divisão dialetal de Minas Gerais Fonte: Zágari (2005, p. 64)

Ainda, ao tecer considerações sobre os estudos que envolvem a temática, destaca-se outro trabalho - Os falares da Bahia e do Espírito Santo: implicações sob os aspectos dialetológicos, de Renato Pereira Aurélio, dissertação defendida em 2012, na Universidade Federal do Espírito Santo (UFES). O autor analisa oito pares de cartas lexicais dos dois atlas: o Atlas Prévio dos Falares Baianos (APFB) e o Atlas Linguístico do Espírito Santo (ALES), tentando estabelecer os caminhos das palavras. Assim conseguiu desmitificar que os capixabas carecem de uma identidade linguística, afirmando que a diversidade cultural é propiciadora da riqueza linguística do Espírito Santo. Sobre as divisões feitas por Nascentes (1953) e Zágari (2005), Aurélio (2012) advoga que existem interferências linguísticas do estado baiano sobre o estado capixaba:

Com relação à classificação de Nascentes (1953) sobre os dialetos brasileiros, apesar de ser confirmada em muitos estudos, demanda análises mais profundas em cada região, com dados representativos de todo território brasileiro (ALTENHOFEN, 2002), a fim de se comprovar o estudo. É o caso do Espírito Santo, classificado apenas no subfalar carioca [...]. Considerandose a hipótese levantada a partir do estudo feito por Zágari (2005), em Minas 
Gerais, em que o autor identifica área do subfalar baiano, é possível dizer que no Espírito Santo ocorre processo semelhante [...] (AURÉLIO, 2012, p. 118119).

Com referência aos trabalhos que fazem alusão aos limites dos falares brasileiros, citase a pesquisa realizada por Ribeiro (2012). Em sua tese de doutorado, a referida autora se propôs a estudar a vitalidade do Falar Baiano, utilizando as elocuções de 244 informantes das 57 localidades - pertencentes à área escolhida e a áreas limítrofes, as quais foram nomeadas como área de controle - compreendidas em 11 estados, distribuídos em quatro regiões do país. Para tal empreendimento, as 13 questões do campo semântico jogos e diversões infantis do Questionário Semântico-Lexical foram alvo de pesquisa sistemática, a saber:

* 155 - Como se chama a brincadeira em que se gira o corpo sobre a cabeça e acaba sentado? (Mímica).

* 156 - Como se chamam as coisinhas redondas de vidro com que os meninos gostam de brincar?

* 157 - Como se chama o brinquedo feito de uma forquinha e duas tiras de borracha (mímica) que os meninos usam para matar passarinho? (Mostrar gravura).

* 158 - Como se chama o brinquedo feito de varetas cobertas de papel que se empina no vento por meio de uma linha?

* 159 -E um brinquedo parecido com o ___ (cf. item 158) também feito de papel, mas sem varetas, que se empina ao vento por meio de uma linha?

* 160 - Como se chama a brincadeira em que uma criança fecha os olhos, enquanto as outras correm para um lugar onde não são vistas e depois essa criança que fechou os olhos vai procurar as outras?

* 161 - Como se chama a brincadeira em que uma criança, com os olhos vendados, tenta pegar as outras?

* 162 - Como se chama uma brincadeira em que uma criança corre atrás das outras para tocar numa delas, antes que alcance um ponto combinado?

* 163 - Como se chama esse ponto combinado?

* 164 - Como se chama uma brincadeira em que as crianças ficam em círculo, enquanto uma outra vai passando com uma pedrinha, uma varinha, um lenço que deixa cair atrás de uma delas e esta pega a pedrinha, a varinha, o lenço e sai correndo para alcançar aquela que deixou cair?

* 165 - Como se chama uma tábua apoiada no meio, em cujas pontas sentam duas crianças e quando uma sobe, a outra desce? (Mímica) (Mostrar gravura). 
166 - Como se chama uma tábua, pendurada por meio de cordas, onde uma criança se senta e se move para frente e para trás? (Mímica) (Mostrar gravura).

* 167 - Como se chama a brincadeira em que as crianças riscam uma figura no chão, formada por quadrados numerados, jogam uma pedrinha (mímica) e vão pulando com uma perna só? SOLICITAR DESCRIÇÃO DETALHADA.

A dissertação de Santos (2016), intitulada "Brincando pelos caminhos do Falar Fluminense", teve a mesma linha de abordagem que a tese de Ribeiro (2012), ou seja, o referido autor buscou a vitalidade de um dos subfalares do Sul, o Falar Fluminense. Para tanto, a pesquisa feita por Santos (2016) baseou-se nas elocuções de 152 informantes, das 35 localidades que perfazem a área estudada e pontos de controle. A extensão do Falar Fluminense, conforme legados de Nascentes (1953), pode ser notada na região sudeste (Rio de Janeiro, Espírito Santo e parte de Minas Gerais), totalizando 26 localidades, sendo 14 pertencentes ao estado do Rio de Janeiro; sete localidades pertencentes a Minas Gerais; e, por fim, cinco localidades do Espírito Santo.

Neste artigo, destacam-se os trabalhos que focalizaram o léxico, a fim de elucidar o conhecimento e o reconhecimento sobre facetas dialetais brasileiras, utilizando os dados do Projeto ALiB, em especial, aqueles que examinaram a questão 166 do QSL, pertencente ao campo semântico jogos e diversões infantis ${ }^{2}$, mas somente os pertencentes aos falares do Sul, ou seja, Ribeiro (2012) e Santos (2016).

\section{Análise de dados}

Os dados utilizados para este artigo foram extraídos das cartas lexicais produzidas pelos já mencionados trabalhos de Ribeiro (2012) e Santos (2016), os quais se valeram do campo semântico dos jogos e diversões infantis, em especial, a questão analisada neste estudo, 166 do QSL: “Como se chama uma tábua, pendurada por meio de cordas, onde uma criança se senta e se move para frente e para trás?" (COMITE NACIONAL DO PROJETO ALiB, 2001, p. 34). Vale dizer que também foi feito o levantamento dos itens lexicais os quais nomeiam a brincadeira em questão, fazendo uma comparação entre os itens encontrados em cada área

\footnotetext{
${ }^{2}$ Torna-se imprescindível destacar a importância dos estudos sobre o campo semântico dos jogos e diversões infantis do QSL - ALiB, pois eles podem fornecer um traçado dialetal do País, podendo confirmar as proposições de Nascentes (1953), na atualidade.
} 
estudada e observando se os itens encontrados são denunciadores de aspectos que possam levar a uma caracterização dessas áreas linguísticas.

Ressalta-se que tais estudos utilizaram o banco de dados do ALiB, com base nos princípios fundamentais da geolinguística contemporânea. Dessa forma, os informantes estão divididos assim: a) duas faixas etárias - faixa I (18 a 30 anos) e faixa II (50 a 65 anos) - b) pelos dois sexos, e de escolaridade - fundamental e universitário, sendo 08 informantes nas capitais e 04 informantes nas localidades do interior, todos naturais das suas cidades, conforme os critérios de seleção estabelecidos pela metodologia do Projeto.

Desse modo, as entrevistas realizadas pelos pesquisadores do ALiB consistem na aplicação do Questionário ALiB (2001), o qual é composto por questionários de vários interesses, a saber: QFF - Questionário Fonético-Fonológico (159 com mais 11 de prosódia); QSL - Questionário Semântico-Lexical (202); QMS - Questionário Morfossintático (49); QP - Questão de Pragmática (04); TDS - Temas para Discurso Semi-dirigido (04); PM - Perguntas Metalinguísticas (06); LE - Texto para Leitura (Parábola dos Sete Vimes / Texto adaptado).

No estudo de Ribeiro (2012) foram documentadas várias denominações. A aplicabilidade da questão em foco foi bastante produtiva, obtendo 275 ocorrências, duas foram de NS/NL/NO, apenas. Com isso, a forma mais produtiva foi balanço, presente em 54 das 57 localidades, conforme Figura 8.

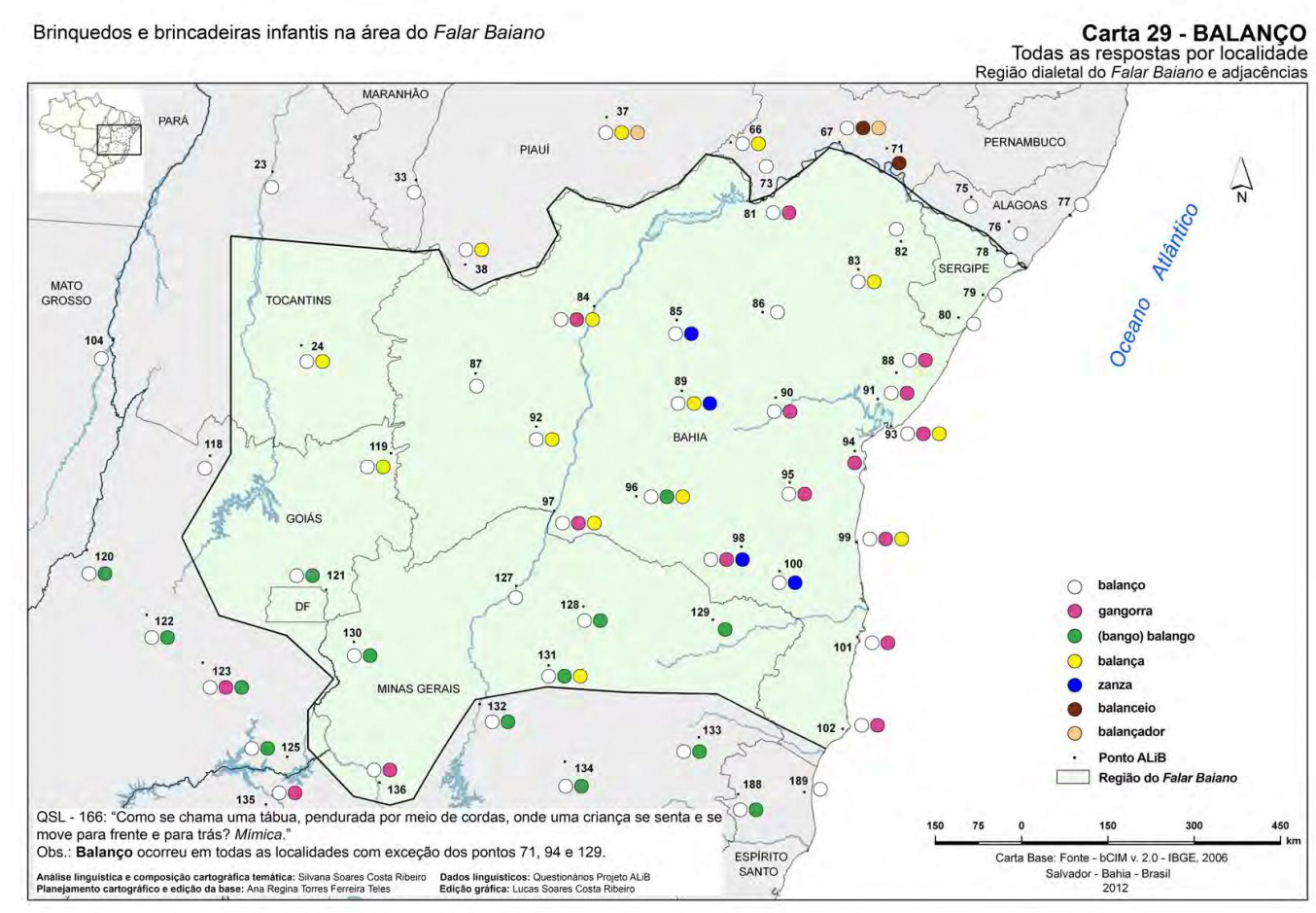


Figura 8: Carta Balanço no Falar Baiano

Fonte: RIBEIRO (2012, p. 528)

A presença das demais lexias é assim observada: gangorra está presente em 16 localidades (28,1\%), seguida de balança e (bango)balango em 14 delas (24,6\%), zanza em quatro $(7,0 \%)$ e balanceio e balançador em duas (3,5\%). Há coocorrência de mais de uma dessas formas lexicais em 40 localidades, como está demonstrado na Figura 8.

\begin{tabular}{cll}
$\begin{array}{c}\text { Tabela 1: Frequência das formas lexicais de balanço- } \\
\text { todas as respostas Agrupamentos lexicais (rótulo) }\end{array}$ & $\begin{array}{l}\text { Total } \\
\text { absoluto }\end{array}$ & $\begin{array}{l}\text { Total } \\
\text { relativo }\end{array}$ \\
$\begin{array}{c}\text { balanço } \\
\text { gangorra } \\
\text { (bango) balango }\end{array}$ & 166 & $60,8 \%$ \\
balança & 39 & $14,3 \%$ \\
zanza & 30 & $11,0 \%$ \\
balanceio & 17 & $6,2 \%$ \\
balançador & 10 & $3,7 \%$ \\
respostas únicas & 5 & $1,8 \%$ \\
& 2 & $0,7 \%$ \\
& 4 & $1,5 \%$ \\
\hline
\end{tabular}

Fonte: Elaboração própria (2017)

Em Santos (2016), conforme Tabela 1, notam-se o levantamento e tratamento estatístico dos dados, a resposta mais conhecida nessa área foi balanço, com 74,7\%. Outras formas que nomeiam esse brinquedo foram coletadas, segundo pode ser visualizado na Tabela 2.

Tabela 2: Frequência das formas lexicais documentadas para QSL/166 - todas as respostas

\begin{tabular}{l|c|c}
\multicolumn{1}{c|}{ Formas lexicais } & $\begin{array}{c}\text { Total } \\
\text { absoluto }\end{array}$ & $\begin{array}{c}\text { Total } \\
\text { relativo }\end{array}$ \\
\hline balanço & 115 & $74,7 \%$ \\
\hline gangorra & 24 & $15,6 \%$ \\
\hline balango & 14 & $9,1 \%$ \\
\hline outras formas & 1 & $0,6 \%$ \\
\hline Total & $\mathbf{1 5 4}$ & $\mathbf{1 0 0 , 0 \%}$ \\
\hline
\end{tabular}

Fonte: Elaboração própria (2017) 
De posse dessas informações, nota-se que o brinquedo, na região em estudo, é conhecido pela forma balanço. No entanto, percebem-se, com menor vitalidade, as formas: gangorra, que obteve 15,6\%, balango, com 9,1\% e, por fim, outras formas $0,6 \%$. Assim, as respostas válidas representam um total absoluto de 154 ocorrências, conforme Figura 9.

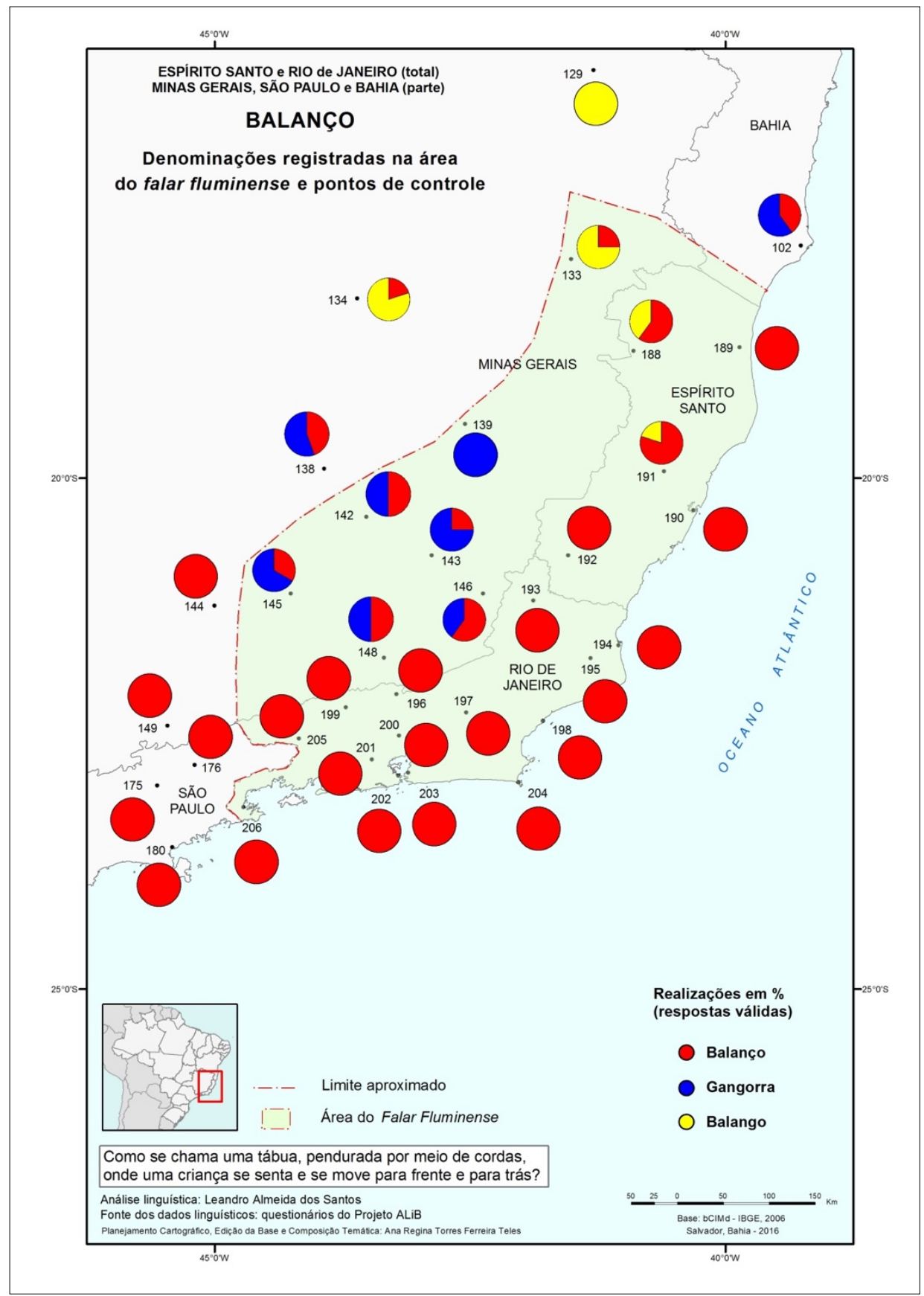

Figura 9: Carta Balanço no Falar Fluminense Fonte: SANTOS (2013, p. 176) 
A partir dessas considerações, no cotejo entre os falares baiano e fluminense, percebe-se uma convergência entre os falares do sul, baiano e fluminense, nos quais a forma balanço foi a que apresentou maior vitalidade. Tal convergência lexical também pode ser notada no trabalho de Santos (2016), quando o referido autor comparou os itens lexicais entre os dois falares para a pergunta 161 do QSL, cobra-cega, a saber:

A partir dessas considerações, nota-se uma tendência de aproximação e unidade na área nomeada por falares do sul, haja vista a coincidência entre os resultados obtidos por Ribeiro (2012) e o estudo de Santos (2016), pois eles aproximam-se pelas lexias cobra-cega, cabra-cega e gata-cega [...] (SANTOS, 2016, p.11).

4 Considerações Finais

Este artigo buscou oferecer informações sobre a delimitação das áreas linguísticas dentro do território brasileiro, que vem sendo alvo de pesquisas por dialetólogos brasileiros, no que tange às proposições feitas por Nascentes (1953), com base nas respostas fornecidas pelos informantes do Projeto ALiB, a fim de investigar a unidade dialetal dos falares do Sul.

Portanto, podem-se tecer algumas considerações, ainda que não definitivas sobre áreas ora analisadas neste estudo, a saber: Balanço, gangorra e balango são formas documentadas nos falares do Sul, Baiano e Fluminense, o que prova uma unidade linguística na área; destacam-se a forma balango, neste item, restrita as cidades mineiras e capixabas, e a resposta gangorra predominantemente em Minas Gerais, no que tange ao Falar Fluminense; existe, pois, a necessidade de estudos mais aprofundados, a fim de poder confirmar a proposição de Nascentes (1953).

Nesse sentido, compreende-se como pertinente e necessária a continuidade de tal investigação, sugerindo que outros campos semânticos sejam testados e/ou outro nível da língua seja alvo de pesquisa, de modo a possibilitar um maior entendimento dos falares das áreas investigadas.

\section{Referências}


AURÉLIO, Renato Pereira. Os Falares da Bahia e do Espírito Santo: implicações sob os aspectos dialetológicos. 2012. 128f. Dissertação (Mestrado em Estudos Linguísticos) Universidade Federal do Espírito Santo, Vitória, 2012.

BARBADINHO NETO, Raimundo (Org.). Estudos Filológicos: volume dedicado à memória de Antenor Nascentes. Rio de Janeiro, Academia Brasileira de Letras, 2003. v. I. 748 p. ilus. (Coleção Antônio de Morais Silva, Estudos de Língua Portuguesa).

COMITÊ NACIONAL DO PROJETO ALiB: Atlas Linguístico do Brasil: Questionários. Londrina: UEL, 2001.

MATTOS e SILVA, Rosa Virginia. (Org.) Salvador: Secretaria de Cultura e Turismo do Estado da Bahia, 2006. p. 319-357.

MOTA, Jacyra Andrade. Áreas dialetais brasileiras. In: Quinhentos Anos de História Linguística do Brasil. CARDOSO, Suzana Alice M.; MOTA, Jacyra Andrade;

NASCENTES, Antenor. Études dialectologiques du Brésil. ORBIS - Bulletin International de Documentat ion Linguistique, Louvain , t. 2, n. 2, p. 438-444, 1953 a.

NASCENTES, Antenor. O Linguajar Carioca. 2. ed. Completamente refundida. Rio de Janeiro. Organização Simões, 1953 b.

RIBEIRO, Silvana Soares Costa. Brinquedos e Brincadeiras Infantis na Área do "Falar Baiano". 2012. 752f. Tese (Doutorado em Letras). Universidade Federal da Bahia, Salvador.

SANTOS, Leandro Almeida dos. Brincando pelos caminhos do Falar Fluminense: um estudo em dois tempos distintos. 2016. 197f. Dissertação (Mestrado em Língua e Cultura) Universidade Federal da Bahia - UFBA - Salvador.

SANTOS, Leandro Almeida dos. Ao findar a brincadeira, o que revelam os dados do ALiB sobre áreas dialetais? Revista Inventário, no 19, p. 1-13, ed. Dezembro 2016.

ZÁGARI, Mário Roberto. Lobo et al. Esboço de um Atlas Lingüístico de Minas Gerais - v. 1. 1ed. Rio de Janeiro: Fundação Casa de Rui Barbosa, 1977. v. 1. 244 p.

ZÁGARI, Mário Roberto Lobo. Os Falares Mineiros: Esboço de um Atlas Lingüístico de Minas Gerais. In: AGUILERA, Vanderci de Andrade. (Org.). A Geolinguística no Brasil - trilhas seguidas, caminhos a percorrer. 1. ed. Londrina: Editora da Universidade Estadual de Londrina, 2005, v. 1, p. 45-72. 